\title{
PENDAMPINGAN MARKETING FUNDING DAN FINANCING PADA BANK PERKREDITAN RAKYAT SYARIAH "X"
}

\author{
Idah Zuhroh $^{1}$, Eris Tri Kurniawati ${ }^{2}$, Muhammad Sri Wahyudi Suliswanto ${ }^{3}$ \\ Universitas Muhammadiyah Malang ${ }^{1,2,3}$
}

\begin{abstract}
PT. BPRS X is a sharia financial institution located in Malang Raya, PT. BPRS X is located in Kota Batu and Malang, Malang Raya area where there are quite a lot of financial institutions, especially BPR institutions in Malang Raya totaling 6 BPRS, 45 BPRs. The existence of a BPR is indeed needed by the community, but its existence must be able to compete with other financial institutions that have stronger capital and have a wider network, as well as a broad market segment, such as Sharia Commercial Banks (BUS) which will also increase micro sector financing. Sharia People's Financing Bank (BPRS). Since 2016, PT BPRS "X" has often suffered losses until now. Quantitative performance achievements at the " $X$ " Sharia Rural Bank (BPRS) in the first semester of 2018 based on the financial statements of the first semester of 2018 showed a downward trend compared to the position of the second semester financial statements of 2017. So there needs to be assistance in marketing funding and financing in This BPRS through several internal HR assistance activities, strengthening communication and presentation skills, formulating marketing strategies. This assistance activity is able to play a role in increasing the amount of musyarakah and Murabahah financing at BPRS " $\mathrm{X}$ ". Neither is the amount of savings or deposits.
\end{abstract}

Keywords: Marketing Funding; Financing;BPRS

\begin{abstract}
Abstrak
PT. BPRS X adalah salah satu lembaga keuangan syariah yang berada di Malang Raya, PT. BPRS X terletak di Kota Batu dan Malang, kawasan Malang Raya terdapat lembaga keuangan yang cukup banyak, khususnya lembaga BPR di Malang Raya berjumlah 6 BPRS, 45 BPR. Keberadaan BPR memang dibutuhkan oleh masyarakat akan tetapi eksistensinya harus mampu bersaing dengan lembaga keuangan lainya yang memiliki modal lebih kuat dan memiliki jaringan lebih luas, juga segmen pasar yang luas, seperti Bank Umum Syariah (BUS) yang juga akan memperbesar pembiayaan sektor mikro tentu dapat mengancam Bank Pembiayaan Rakyat Syariah (BPRS). Sejak tahun 2016, PT BPRS "X" seringkali mengalami kerugian hingga sekarang. Pencapaian kinerja secara kuantitatif pada Bank Perkreditan Rakyat Syariah (BPRS) "X" di semester pertama tahun 2018 berdasarkan laporan keuangan kinerja semester pertama tahun 2018 menunjukkan trend penurunan dibandingkan dengan posisi laporan keuangan semester 2 tahun 2017. Sehingga perlu adanya pendampingan marketing funding maupun financing pada BPRS ini melalui beberapa kegiatan pendampingan SDM internal, penguatan kemampuan komunikasi dan presentasi, penyusunan strategi marketing. Kegiatan pendampingan ini mampu berperan meningkatkan jumlah pembiayaan musyarakah maupun Murabahah di BPRS “X”. Begitupula jumlah tabungan maupun deposito.
\end{abstract}

Kata Kunci: Marketing Funding, Financing, BPRS

\section{PENDAHULUAN}

PT. BPRS X adalah salah satu lembaga keuangan syariah yang berada di Malang Raya, PT. BPRS X terletak di Kota Batu dan Malang, kawasan Malang Raya terdapat lembaga keuangan yang cukup banyak, khususnya lembaga BPR di Malang Raya berjumlah 6 BPRS, 45 BPR (ojk.go.id). Keberadaan BPR memang dibutuhkan oleh masyarakat akan tetapi eksistensinya harus mampu bersaing dengan lembaga keuangan lainya yang memiliki modal lebih kuat dan memiliki jaringan lebih luas, juga segmen pasar yang luas, seperti Bank Umum Syariah (BUS) yang juga akan memperbesar pembiayaan sektor mikro tentu dapat mengancam Bank Pembiayaan Rakyat Syariah (BPRS).

Sejak tahun 2016, PT BPRS "X” seringkali mengalami kerugian hingga sekarang. (Ramadhani, Sufian, \& Soesanto, 2013) Pencapaian kinerja secara kuantitatif pada Bank Perkreditan Rakyat Syariah (BPRS) "X" disemester pertama tahun 2018 berdasarkan laporan keuangan kinerja semester pertama tahun 2018 menunjukkan trend penurunan dibandingkan dengan posisi laporan keuangan semester 2 tahun 2017. Pada sisi penyaluran dana kepada masyarakat (financing) terjadi penurunan realisasi dari target sebesar $0.18 \%$, penurunan ini dikarenakan pada semester 1 tahun 2018 pembiayaan-pembiayaan baru belum sesuai harapan. Penurunan Asset ini disebabkan beban biaya lebih tinggi dari pada pendapatan yang diterima. Berdasarkan daftar target dan realisasi pembiayaan per kantor cabang di semester pertama bulan Juni tahun 2018 juga mengalami penurunan.

${ }^{1}$ idah@umm.ac.id 

Wahyudi)

Tabel 1. Daftar Realisasi Pembiayaan Tahun 2018 (Dalam Rupiah)

\begin{tabular}{ccccc}
\hline Bulan & Kantor Pusat & $\begin{array}{c}\text { Kantor Cabang } \\
\text { Junrejo }\end{array}$ & $\begin{array}{c}\text { Kantor Cabang } \\
\text { Malang }\end{array}$ & Total \\
\hline Jan & 56.500 .000 & 218.000 .000 & 220.300 .000 & 494.800 .000 \\
\hline Feb & 473.000 .000 & 136.000 .000 & 162.900 .000 & 771.900 .000 \\
\hline Mar & 402.500 .000 & 308.000 .000 & 219.700 .000 & 930.200 .000 \\
\hline Apr & 331.500 .000 & 226.000 .000 & 191.700 .000 & 749.200 .000 \\
\hline Mei & 258.500 .000 & 293.200 .000 & 225.100 .000 & 776.800 .000 \\
\hline Jun & 73.500 .000 & 56.600 .000 & 197.600 .000 & 327.700 .000 \\
\hline Jul & 179.000 .000 & 195.500 .000 & 310.500 .000 & 685.000 .000 \\
\hline Aug & 180.500 .000 & 112.500 .000 & 214.900 .000 & 507.900 .000 \\
\hline Sep & 272.500 .000 & 230.500 .000 & 79.500 .000 & 582.500 .000 \\
\hline Okt & 369.500 .000 & 176.000 .000 & 149.000 .000 & 694.500 .000 \\
\hline Nov & 220.500 .000 & 317.200 .000 & 210.000 .000 & 747.700 .000 \\
\hline Des & 292.500 .000 & 151.300 .000 & 304.500 .000 & 748.300 .000 \\
\hline Jumlah & $\mathbf{3 . 1 1 0 . 0 0 0 . 0 0 0}$ & $\mathbf{2 . 4 2 0 . 8 0 0 . 0 0 0}$ & $\mathbf{2 . 4 8 5 . 7 0 0 . 0 0 0}$ & $\mathbf{8 . 0 1 6 . 5 0 0 . 0 0 0}$ \\
\hline
\end{tabular}

Pada akhir periode tahun 2018 penyaluran dana kepada masyarakat berupa pembiayaan sebagai pengerak di sektor-sektor perekonomian sebesar Rp 8.016.500. ribu tercapai 52.37\% dari Rp 18.615.865 ribu dan mengalami penurunan sebesar Rp.583.847 ribu atau 5.65\% dari realisasi tahun 2017. penurunan ini disebabkan karena pelunasan pembiayaan lebih besar dari realisasi pembiayaan baru. Disamping itu tahun 2018 melakukan Hapus buku atas pembiayaan sebesar Rp. 337.334 ribu juga berpengaruh terhadap penurunan jumlah pembiayaan. Pembiayaan yang bermasalah (NPF) 35.75\% atau sebesar Rp 3.485.287. ribu dengan cadangan pembiayaan bermasalah sebesar Rp. 635.040. ribu.Memperhatikan hal itu. Direksibeserta karyawan Bank Pembiayaan rakyat Syariah "X" Batu sudah berupaya dan berdoa agar peningkatkan penyaluran Pembiyaan Yang Diberikan. minimal sesuai dengan target yang telah dibuat dalam Rencana Bisnis BPRS. dan mengoptimalkan penyelesaian Pembiayaan bermasalah dan Pembiayaan yang telah dihapus buku.dengan harapan rentabilitas BPRS bisa meningkat.

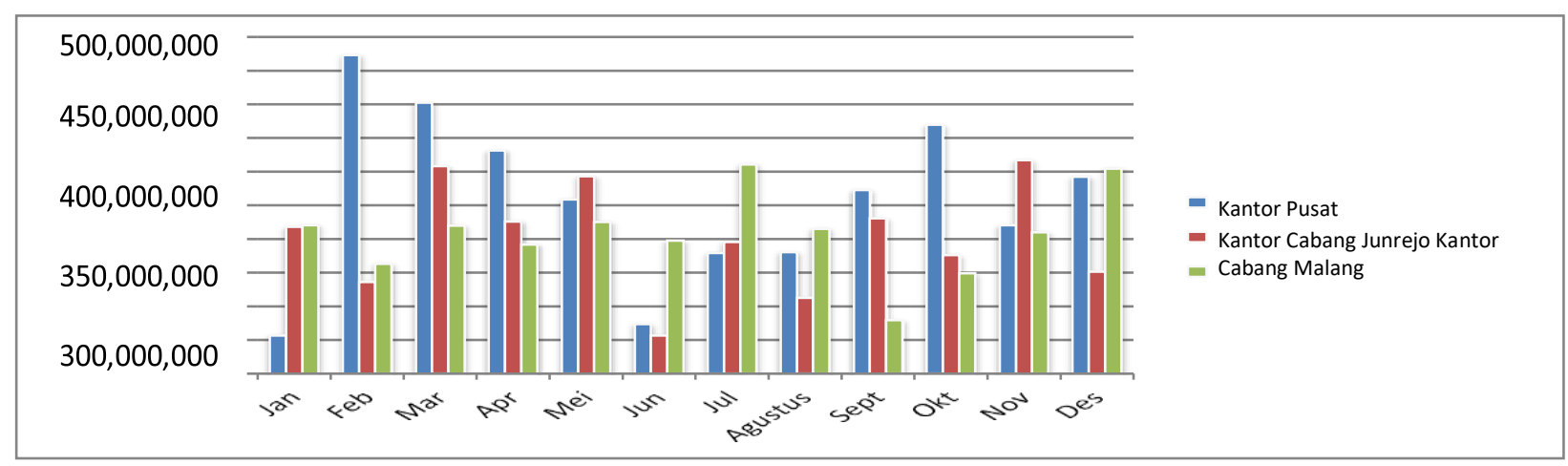

Gambar 1. Realisasi Pembiayaan per cabang

Sementara dari sisi penghimpunan dana masyarakat (funding) yaitu untuk produk tabungan, meskipun menunjukkan tren kenaikan, akan tetapi belum memenuhi target yang diharapkan. Tidak tercapainya target tersebut, tampaknya masyarakat yang berada di sekitar wilayah kerja PT BPRS "X" Batu masih lebih memilih untuk menyimpan dananya dalam bentuk Deposito/Simpanan Berjangka dengan memperoleh imbalan yang lebih memadai. Selain itu, BPRS " $X$ " masih belum ada tenaga kerja bidang 
marketing khusus penghimpunan dana mayarakat sehingga masih belum optimalnya bagian funding untuk menggarap potensi dana simpanan berupa tabungan yang ada di masyarakat.

Tabel 2. Realisasi dan Target Penghimpunan Tabungan tahun 2018 (Dalam Rupiah)

\begin{tabular}{cccc}
\hline Bulan & Tabungan & Target & Pencapaian \\
\hline Jan & 3.092 .712 .767 & 2.979 .284 .944 & $103.80 \%$ \\
\hline Feb & 3.229 .279 .992 & 3.009 .683 .063 & $107.29 \%$ \\
\hline Mar & 3.347 .095 .643 & 3.040 .391 .338 & $110.08 \%$ \\
\hline Apr & 3.231 .614 .319 & 3.071 .412 .936 & $105.22 \%$ \\
\hline Mei & 3.116 .912 .667 & 3.102 .751 .051 & $100.45 \%$ \\
\hline Jun & 2.979 .183 .581 & 3.134 .408 .914 & $95.04 \%$ \\
\hline Jul & 2.854 .431 .772 & 3.166 .389 .788 & $90.15 \%$ \\
\hline Aug & 2.929 .132 .402 & 3.198 .696 .967 & $91.57 \%$ \\
\hline Sep & 3.029 .394 .116 & 3.231 .333 .782 & $93.75 \%$ \\
\hline Okt & 2.998 .357 .923 & 3.264 .303 .595 & $91.85 \%$ \\
\hline Nov & 2.878 .962 .145 & 3.297 .609 .805 & $87.30 \%$ \\
\hline Des & 3.068 .493 .326 & 3.331 .255 .843 & $92.11 \%$ \\
\hline
\end{tabular}

Pertumbuhan dana dalam bentuk deposito pun pada semester 1 tahun 2018 menunjukkan tren yang stagnan. Namun sampai dengan akhir periode Tahun 2018 penghimpunan dana masyarakat dalam bentuk Deposito bias mencapai target yang ditetapkan yaitu sebesarRp. 7.347 .694 atau sebesar 133.85\% dari target sebesar Rp. 5.489.550. Adapun 10 (sepuluh) Deposan terbesar adalah sebesar Rp. 4.110 .000 atau 55.94\% dari total Deposito, termasuk 2 (dua) deposan dari Pihak UMM sebesar Rp. 2.000.000. Jumlah penghimpunan dana Deposito ditahun 2018 sebesar Rp. 3.377.277 sedangkan yang melakukan pencairan deposito sebesar Rp. 631.500. Adapun Realisasi dan target penghimpunan deposito dapat dilihat pada tabel 3.

Tabel 3. Realisasi dan Target Penghimpunan Deposito

\begin{tabular}{cccc}
\hline Bulan & Deposito & Target & Pencapaian \\
\hline Jan & 4.792 .416 .500 & 5.194 .794 .030 & $92.25 \%$ \\
\hline Feb & 4.851 .416 .500 & 5.216 .379 .993 & $93.00 \%$ \\
\hline Mar & 6.776 .416 .500 & 5.238 .879 .978 & $129.35 \%$ \\
\hline Apr & 6.779 .566 .500 & 5.262 .332 .666 & $128.83 \%$ \\
\hline Mei & 6.396 .693 .500 & 5.286 .778 .588 & $120.99 \%$ \\
\hline Jun & 6.346 .693 .500 & 5.312 .260 .218 & $119.47 \%$ \\
\hline Jul & 6.381 .693 .500 & 5.338 .822 .077 & $119.53 \%$ \\
\hline Aug & 6.794 .693 .500 & 5.366 .510 .833 & $126.61 \%$ \\
\hline Sep & 6.785 .693 .500 & 5.395 .375 .414 & $125.77 \%$ \\
\hline Okt & 6.827 .693 .500 & 5.425 .467 .125 & $134.65 \%$ \\
\hline Nov & 7.348 .693 .500 & 5.456 .839 .768 & $133.85 \%$ \\
\hline Des & 7.347 .693 .500 & 5.489 .649 .770 &
\end{tabular}

Adapun terkait ketersediaan Sumber Daya Manusia (SDM) pada BPRS “X” untuk 3 kantor cabang yang beroperasi (Kantor Malang, Kantor Junrejo, dan Kantor Batu) hanya memiliki 26 pegawai dan 
direktur BPRS "X" telah menyampaikan bahwa sangat kekurangan tenaga pemasar baik untuk produk funding maupun produk financing.

Dengan memperhatikan bahwa, kontribusi penempatan dana akan memberikan pengaruh terhadap nilai pembiayaan yang disalurkan kepada masyarakat maka diperlukan tenaga marketing yang memiliki kompetensi handal untuk menghimpun produk dana (funding) dan marketing untuk menyalurkan pembiayaan kepada masyarakat (financing) menuju perbankan yang sehat dan kuat. BPRS "X" membutuhkan penguatan untuk tenaga marketing funding dan financing guna meningkatkan performa kinerja diperiode kedepan (Ramadhani, Sufian, \& Soesanto, 2013).

Dalam kerangka mewujudkan pendanaan yang kuat bagi BPRS " $X$ " guna menunjang penyaluran pembiayaan kepada masyarakat sesuai dengan nilai yang ditargetkan, tim pengabdian FEB UMM memberikan pendampingan dengan melibatkan peran aktif mahasiswa Program Studi Perbankan dan Keuangan Program Diploma III dengan mengintegrasikan praktek lapang untuk mensupport tenaga marketing funding dan financing pada BPRS "X” (Zuhroh, 2012; Zuhroh, 2012).

\section{MATERI DAN METODE PELAKSANAAN}

Perluasan Market Share untuk produk Funding dan Financing, serta dalam rangka mewujudkan pendanaan yang kuat bagi BPRS " $X$ " guna menunjang penyaluran pembiayaan kepada masyarakat sesuai dengan nilai yang ditargetkan, tim pengabdian FEB UMM memberikan pendampingan dengan melibatkan peran aktif mahasiswa Program Studi Perbankan dan Keuangan Program Diploma III dengan mengintegrasikan praktek lapang untuk mensupport tenaga marketing funding dan financing pada BPRS "X" (Zuhroh, 2012; Zuhroh, 2012). Adapun metode kegiatan dapat dilihat pada tabel 4.

Tabel 4. Metode Kegiatan

\begin{tabular}{lll}
\hline $\begin{array}{c}\text { Tujuan Kegiatan } \\
\text { Program }\end{array}$ & & \\
\hline Pendampingan & 1. & Melakukan desain kelompok/ Tim Mahasiswa \\
SDM Internal & 2. & Penjelasan Product Knowledge yang akan ditawarkan \\
\hline Penguatan & 1. & Melakukan Penjelasan mengenai Teknik Komunikasi. \\
Communication & 2. & Praktik Communication Skill \\
Skill & & \\
\hline Penguatan & 1. & Melakukan Penjelasan mengenai Teknik presentasi yang baik. \\
Presentation Skill & 2. & Praktik Presentasi \\
\hline Penyusunan & 1. & Penjelasan Marketing Strategy \\
Marketing & 2. & Penyusunan Marketing Strategy \\
Startegy & & \\
\hline
\end{tabular}

\section{HASIL DAN PEMBAHASAN}

\section{Pendampingan SDM Internal}

SDM BPRS “ $X$ ” mengalami keterbatasan jumlah akibat menurunnya kinerja keuangan BPRS "X”. Maka, perlu dilakukan penambahan 3 orang Account Officer untuk mengejar target pertumbuhan pembiayaan. Penambahan tersebut akan dialokasikan pada kantor pusat, cabang Junrejo dan Malang. Selain itu, perlu dilakukan pelatihan untuk meningkatkan kemampuan SDM BPRS "X". Untuk meningkatkan kapasitas kompetensi dan profesionalisme sumber daya manusia perusahaan perlu merealisasi programprogram pengembangan kualitas SDM melalui beberapa kegiatan pendidikan dan pelatihan (Rachmawati, 2017; Pratiwi \& Cahyono, 2018; Yusran \& Sodik, 2019). Kegiatan pendidikan dan pelatihan yang diikuti dapat secara in-house maupun dalam bentuk partisipasi pada even pengembangan SDM oleh Lembaga Pendidikan dan pelatihan lain. Beberapa kegiatan yang dapat direalisasikan oleh BPRS " $X$ " adalah sebagai beriku: Pertama, menyelenggarakan pelatihan sendiri berupa pemantapan Aplikasi Ideb yang diikuti Direktur, Ka Div. Operasional, Kepala Cabang dan 3 staf operasional. Kedua, mengirimkan Direksi, Kepala Cabang, maupun staf untuk mengikuti pelatihan yang diselenggarakan oleh OJK maupun Asbisindo sesuai dengan undangan kepersertaan pelatihan.

\section{Penguatan Communication Skill}

Komunikasi adalah proses pertukaran informasi, pendapat, perasaan atau ide melalui lisan atau tulisan agar pesan yang disampaikan mencapai sasaran atau dipahami oleh orang lain. Komunikasi yang 
bermakna adalah komunikasi yang efektif dimana proses komunikasi tersebut berhasil mencapai sasaran dengan feedback (respon) yang sesuai dengan tujuan individu berkomunikasi. Kemampuan untuk mengungkapkan keinginan, ide, perasaan, pikiran atau pendapat seseorang sehingga dapat dipahami dan dimengerti oleh orang lain ini merupakan hal yang penting dalam lingkungan pekerjaan atau organisasi. Lemahnya koordinasi dan komunikasi yang tidak efektif berpotensi menimbulkan masalah besar di tempat kerja yang akan mempengaruhi kinerja perusahaan. Kurangnya trust dan ketidakpahaman terhadap karakter rekan kerja (atasan, bawahan, klien, pelanggan) menjadi titik mulai masalah ini. Oleh karena itu, komunikasi yang efektif memegang peran penting dalam memasarkan produk bank (Fahrurazi, Ghalib, \& Arifin, 2016; Lubis, 2016), hal ini tentu dapat diaplikasikan pada BPRS X agar produknya semakin diminati masyarakat.

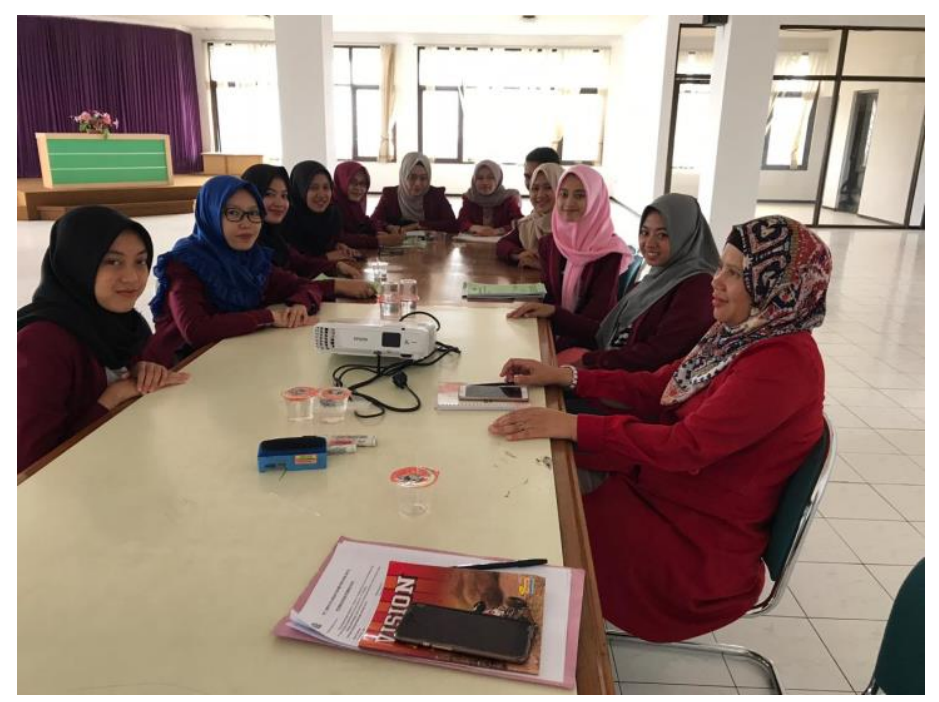

Gambar 2. Penjelasan Product Knowledge BPRS "X" dan Penguatan Communication Skill dari Pihak BPRS " $X$ " Kepada Kelompok Marketing Funding dan Marketing Financing

\section{Penguatan Presentation Skill}

Presentasi efektif akan membuat seseorang mampu menyampaikan informasi secara sistematis, singkat dan jelas (Susanto, 2015). Tujuannya beragam dari mulai yang sifatnya informatif (pesan) sampai dengan persuasif (pesan dan kesan). Presentasi efektif dimulai dari menyusun materi presentasinya, penggunaan media atau aplikasi program untuk membuat penampilan presentasi atraktif, cara menyampaikan presentasi, dan menanggapi audience presentasi. Kegiatan ini tentu akan memberikan pemahaman kepada mitra mengenai keseluruhan presentasi efektif agar mudah dipahami oleh calon nasabah yang diharapkan meningkatkan minat nasabah pada BPRS X.

\section{Penyusunan Marketing Startegy}

Penyusunan marketing strategi meliputi segmentasi nasabah berdasarkan jenis nasabah baru ataupun nasabah existing, perorangan ataupun perusahaan, usia, status pernikahan, jenis kelamin, pekerjaan. Pengklasifikasian tersebut akan mempermudah kelompok mahasiswa dalam memasarkan produknya karena sudah terpetakan. Kemudian dari segementasi tersebut akan ditentukan target market yang akan dijadikan sasaran. Selanjutnya positioning yaitu kelompok mahasiswa mengeti perbedaan produk yang akan ditawarkan dengan produk pesaing, kemudian keuntungan yang akan didapatkan nasabah jika bergabung dengan produk yang ditawarkan, dan manfaat yang dirasa nasabah. Kelompok mahasiswa harus menguasai tiga kunci marketing tersebut agar dapat meningkatkan minat nasabah (Andespa, 2016; Wowiling, Tumbuan, \& Wenas, 2017). Pada era digital saat ini, media pemasaran juga dapat ditingkatkan dengan memanfaatkan teknologi informasi yang berkembang di masyarakat (Malik, Oktavia, Suliswanto, \& Anindyntha, 2020), sehingga pengelola BPRS juga harus merespon perubahan ini untuk meningkatkan kinerja pemasaran produk BPRS. 


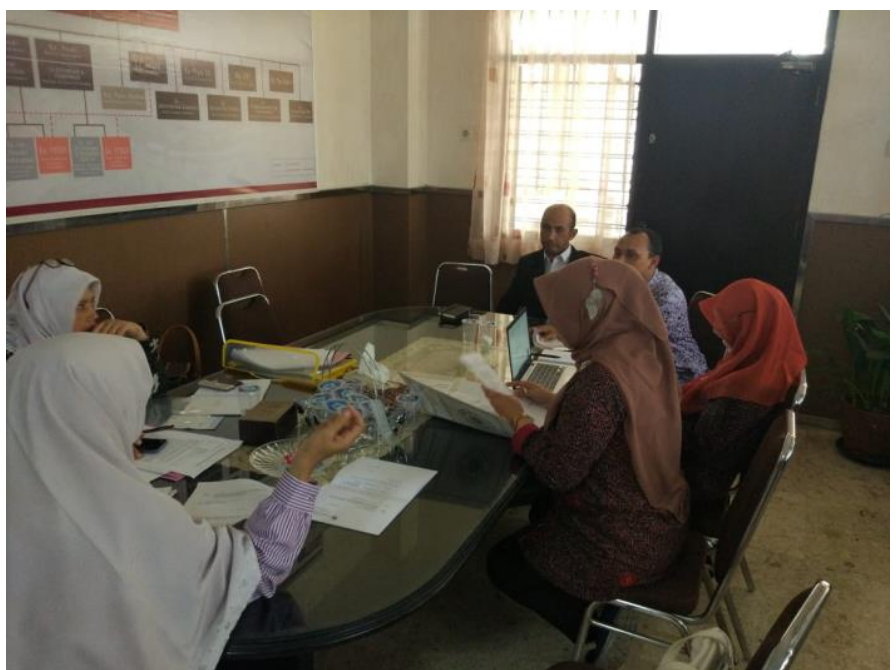

Gambar 3. Koordinasi Tim Pegabdian dengan Direktur Operasional BPRS "X”terkait Marketing Strategy Produk Funding dan Financing

\section{KESIMPULAN DAN SARAN}

Kegiatan pendampingan ini mampu berperan meningkatkan jumlah pembiayaan musyarakah maupun Murabahah di BPRS "X”. Pada bulan oktober sampai desember 2019 untuk murabahah meningkat dari 10,9 Milyar menjadi 11,3 Milyar dan pembiayaan Musyarakah meningkat dari 632 juta menjadi 883 juta. Dengan demkian, tindak lanjut setelah program ini masih perlu dilaksanakan oleh pengelola yaitu dengan mengembangkan jangkauan pemasaran tidak hanya berbasis door to door tetapi dapat melalui media digital.

\section{UCAPAN TERIMA KASIH}

Terimakasih untuk PPEBK FEB UMM yang memberikan pendanaan kegiatan pengabdian ini.

\section{REFERENSI}

Andespa, R. (2016). Strategi Industri Perbankan di Sumatera Barat: Pemilihan Segmentasi Pasar untuk Menciptakan Pelayanan yang Memuaskan. Maqdis: Jurnal Kajian Ekonomi Islam, 1(1), 47-62.

Fahrurazi, R., Ghalib, S., \& Arifin, H. (2016). Pengaruh Komunikasi dan Budaya Organisasi terhadap Kinerja Karyawan PT. Bank Pembangunan Daerah Kalimantan Selatan Wilayah Banjarmasin. Jurnal Bisnis dan Pembangunan, 1 (1), 37-46.

Lubis, A. S. (2016). Pengaruh Komunikasi Dan Manajemen Hubungan Karyawan Terhadap Kinerja Karyawan Pada Pt. Bank Panin Dubai Syariah Cabang Medan. KBM (Jurnal Konsep Bisnis Dan Manajemen), 3(1), 1-11.

Malik, N., Oktavia, A., Suliswanto, M. S., \& Anindyntha, F. A. (2020). Financial banking performance of ASEAN-5 countries in the digital era. Jurnal Keuangan dan Perbankan, 24(1), 117-127.

Pratiwi, S. L., \& Cahyono, H. (2018). Pengaruh Pendidikan dan Pelatihan Terhadap Peningkatan Kualitas SDM Bank Syariah Pada Bank Syariah Mandiri KCP Lamongan. Jurnal Ekonomi Islam, 1(2), 145-153.

Rachmawati, R. W. (2017). pengaruh pelatihan dan motivasi kerja terhadap kinerja karyawan PT. bank BJB kantor cabang suci Bandung. Jurnal Manajemen dan Pemasaran Jasa, 9(1), 1-16.

Ramadhani, A. F., Sufian, S., \& Soesanto, H. (2013). Analisis pengaruh promosi, efek komunitas, reputasi perusahaan, harga, dan kompetensi tenaga marketing terhadap minat konsumen mengambil kredit di PT BPR Weleri Makmur Semarang. Semarang: Doctoral dissertation, Diponegoro University. 
Susanto, H. (2015). Communication Skills” Sukses Komunikasi, Presentasi dan Berkarier! Yogyakarta: Deepublish.

Wowiling, Y. G., Tumbuan, A. L., \& Wenas, R. S. (2017). Analisis Segmentation, Targeting Dan Positioning Kartu Kredit (Studi Pada Pengguna Kartu Kredit Bri-Touch Pt. Bank Rakyat Indonesia Tbk (Persero) Kantor Wilayah Manado). Jurnal EMBA: Jurnal Riset Ekonomi, Manajemen, Bisnis dan Akuntansi, 5(3), 3250-3261.

Yusran, A., \& Sodik, S. (2019). Analisis Pengaruh Pengembangan Sumber Daya Manusia Terhadap Kinerja Karyawan Pada Pt. Bank Bni Cabang Utama Kendari. JIM (Jurnal Ilmu Manajemen), 4(3), 1-11.

Zuhroh, I. (2012). Pengenalan Operasional Bank Syariah Melalui Laboratorium Riil Banking. Media Trend, 7(2), 43-57.

Zuhroh, I. (2012). Penguatan Laboratorium Bank Syariah Untuk Mendukung Perkembangan Industri Keuangan Syariah. Ekonomika-Bisnis: Jurnal Penelitian dan Pemikiran 3 (1) , 13-28. 
